\title{
SPC (Statistical Process Control) Fase II Diagram Kendali Cusum (Cumulative Sum) Nonparametrik Berdasarkan Statistik Mann- Whitney Pada Data Harga Saham PT X
}

\author{
Zakiyatis Salmaini* $^{*}$ \\ Prodi Statistika, Fakultas Matematika dan Ilmu Pengetahuan Alam, \\ Universitas Islam Bandung, Indonesia. \\ *zakiyatiss@gmail.com
}

\begin{abstract}
Attracting the interest and trust of many investors in a company requires an attraction in the form of quality and stability of the performance of a company. Through stock data, quality measurements can be made using control charts, so that it can be seen whether a company's performance is stable or not. In the conventional control chart, it is assumed that the data is normally distributed, but in practice it is often found that the data does not meet the normality assumption. In this paper, we will discuss the CUSUM control chart nonparametric based on the Mann-Whitney Statistic on the stock price data of (PT). X. This method is a stage of the stage of the SPC phase II which is used to detect small shifts with no assumptions, and the nominal value of the mean is unknown. From this research it was concluded that in the stock close price data there was a downtrend shift in the average process on the first day of monitoring which indicated that at the 44th point the stock price of (PT). X experienced a downtrend, so that the stock price of (PT). X was declared in an out-of-control state.
\end{abstract}

Keywords: Nonparametric Control Chart, Mann-Whitney, Stocks, SPC Phase II.

\begin{abstract}
Abstrak. Menarik minat dan kepercayaan banyak investor terhadap suatu perusahaan dibutuhkan suatu daya tarik berupa kualitas dan kestabilan kinerja dari suatu perusahaan. Melalui data saham dapat dilakukan pengukuran kualitas dengan menggunakan diagram kendali, sehingga dapat diketahui apakah kinerja suatu perusahaan dalam keadaan stabil atau tidak. Pada jenis diagram kendali konvensional diasumsikan data berdistribusi normal, namun pada praktiknya sering ditemukan data tidak memenuhi asumsi kenormalan. Pada makalah ini akan dibahas mengenai diagram kendali CUSUM (Cumulative Sum) nonparametrik berdasarkan statistik Mann-Whitney pada data harga saham PT X. Metode ini merupakan tahapan dari proses SPC (Statistical Process Control) Fase II yang digunakan untuk mendeteksi pergeseran kecil pada rata-rata proses dengan tidak terdapat asumsi yang harus dipenuhi, serta nilai nominal rata-rata yang digunakan tidak harus diketahui. Dari penelitian yang dilakukan disimpulkan bahwa pada data harga close saham terjadi pergeseran ratarata proses ke bawah pada pemantauan hari pertama yang mengindikasikan pada titik ke-44 harga saham (PT). X mengalami downtrend (tren menurun), sehingga harga saham (PT). X dinyatakan dalam keadaan tidak terkendali.
\end{abstract}

Kata Kunci: Diagram Kendali Nonparametrik, Mann-Whitney, Saham, SPC Fase II. 


\section{A. Pendahuluan}

Menurut edusaham.com (Tim Edusaham, 2019) salah satu hal yang perlu diperhatikan oleh investor sebelum berinvestasi adalah dengan melakukan analisis pada trendline saham dari perusahaan yang bisa dijadikan sebagai pedoman untuk melakukan penganalisisan arah tren pergerakan harga saham, yang terdiri dari tren naik (uptrend), tren turun (downtrend), dan tren datar (sideways) yang disajikan dalam bentuk grafik pada suatu bursa saham. Menarik minat dan kepercayaan banyak investor terhadap suatu perusahaan dibutuhkan suatu daya tarik berupa kualitas dan kestabilan kinerja dari suatu perusahaan. Melalui data saham dapat dilakukan pengukuran kualitas dari suatu perusahaan dengan menggunakan diagram kendali, sehingga dapat diketahui apakah kinerja suatu perusahaan dalam keadaan stabil atau tidak.

Pada diagram kendali yang perlu diperhatikan tidak hanya semata apakah suatu proses dalam keadaan terkendali atau tidak yang ditandai dengan adanya titik yang di luar batas kendali, namun juga perlu diperhatikan apabila dalam suatu proses terjadi perubahan titik yang berguna untuk mendeteksi terjadinya pergeseran rata-rata dan varians pada prosesnya. Pada penelitian ini akan fokus pada pemantauan proses rata-rata, dengan mengasumsikan bahwa proses variansnya stabil. Diagram kendali yang pada umumnya biasa digunakan untuk menentukan apakah suatu proses dalam keadaan terkendali atau tidak adalah diagram kendali Shewhart, namun ketika digunakan untuk mendeteksi pergeseran rata-rata, diagram kendali Shewhart hanya mampu mendeteksi pergeseran besar. Sehingga untuk mendeteksi pergeseran yang relatif kecil maka dibutuhkan jenis diagram kendali lainnya. Berdasarkan literatur, disebutkan bahwa metode alternatif pada diagram kendali yang dapat digunakan untuk mendeteksi pergeseran yang kecil pada rata-rata proses yaitu diagram kendali CUSUM (Cumulative Sum).

Pada penelitian ini akan digunakan jenis diagram kendali CUSUM (Cumulative Sum), Wang dkk (2016) mengajukan sebuah diagram kendali CUSUM nonparametrik menggunakan statistik Mann-Whitney untuk mendeteksi pergeseran kecil pada rata-rata proses. Di mana pada metode yang diajukan oleh Wang dkk ini nilai nominal rata-rata yang digunakan tidak harus diketahui, kemudian tidak ada asumsi yang harus dipenuhi ketika menggunakan metode tersebut. Pada penelitian yang dilakukan oleh Wang dkk (2016) disimpulkan bahwa berdasarkan perbandingan simulasi kinerjanya diperoleh bahwa diagram kendali CUSUM nonparametrik berdasarkan statistik Mann-Whitney sedikit lebih efektif dibandingkan beberapa diagram kendali nonparametrik lainnya.

Berdasarkan penelitian yang dilakukan oleh Wang dkk (2016) maka pada skripsi ini akan dilakukan pemodelan sebuah diagram kendali CUSUM nonparametrik berdasarkan statistik Mann-Whitney pada data harga saham (PT). X.

\section{B. Metodologi Penelitian \\ Data}

Data yang digunakan dalam menerapkan metode pada penelitian ini adalah data sekunder, yang diperoleh dari data saham yang dipublikasikan oleh yahoo finance. Data tersebut berisi informasi harga saham perusahaan yang terdiri dari harga pembukaan, harga tertinggi, harga terendah, harga penutupan, dan volume. Untuk penelitian ini akan digunakan harga penutupan (closing price) dari harga saham Perusahaan NO.

\section{SPC (Statistical Process Control) Fase I}

Menurut Graham dkk (2009), fase I dari SPC merupakan tahap yang sangat penting, karena merupakan kunci yang menentukan keberhasilan dari proses SPC secara keseluruhan, yang dilakukan secara berulang jika terdapat data proses yang dinyatakan dalam keadaan tidak terkendali. Pada penelitian ini, untuk fase I akan digunakan metode yang diajukan oleh Goedhart dkk (2019) pada Damayanti,F. (2020), yaitu diagram kendali nonparametrik berdasarkan interval toleransi nonparametrik menggunakan statistik order. Di mana diagram kendali ini dapat diterapkan pada pengujian sampel dalam bentuk individu maupun dalam bentuk subgroup dengan berbagai jenis ukuran sampel.

Sekumpulan data yang terdiri dari $X_{1}, X_{2}, \ldots, X_{l}$ yang merupakan sampel acak yang berdistribusi kontinu, kemudian diurutkan sesuai statistik order dengan urutan terkecil hingga 
terbesar yaitu $X_{(1)}<X_{(2)}<\cdots<X_{(l)}$. Kemudian tentukan ukuran sampel minimum $l_{2}\left(\alpha_{t o l}, p\right)$ untuk interval toleransi dua sisi $\left[X_{(r)}, X_{(s)}\right]$ berdasarkan tabel yang telah disediakan oleh Goedhart dkk (2019) pada Tabel 1.

Tabel 1 Ukuran Sampel Minimum

Sumber: Goedhart dkk (2019)

\begin{tabular}{|c|c|c|c|}
\hline \multirow{2}{*}{$\boldsymbol{\alpha}_{\text {tol }}$} & \multicolumn{3}{|c|}{$\boldsymbol{p}$} \\
\cline { 2 - 4 } & $\mathbf{0 , 2}$ & $\mathbf{0 , 1}$ & $\mathbf{0 , 0 5}$ \\
\hline $\mathbf{0 , 0 5}$ & 59 & 77 & 93 \\
\hline $\mathbf{0 , 0 1}$ & 299 & 388 & 473 \\
\hline $\mathbf{0 , 0 0 5}$ & 598 & 777 & 947 \\
\hline $\mathbf{0 , 0 0 2 7}$ & 1109 & 1440 & 1756 \\
\hline
\end{tabular}

Di mana $p$ merupakan nilai kriteria peluang sebagai kompensasi dari karakter acak dari kinerja diagram kendali yang memenuhi kriteria berikut:

$$
P\left(1-P(B \widehat{K} B \leq X \leq B \widehat{K} A)>\alpha_{t o l}\right)=p
$$
kendali.

$B \widehat{K} B$ dan $B \widehat{K} A$ merupakan nilai estimasi untuk batas-batas kendali pada diagram

Bandingkan jumlah data sampel yang tersedia dengan ukuran sampel minimum $l_{2}\left(\alpha_{t o l}, p\right)$ yang dibutuhkan untuk interval toleransi dua sisi pada tabel 2.1, dengan aturan keputusan jika $l \geq l_{2}\left(\alpha_{t o l}, p\right)$ maka lakukan interpolasi, sedangkan jika $l<l_{2}\left(\alpha_{t o l}, p\right)$ maka lakukan ekstrapolasi.

Langkah-langkah untuk interpolasi:

1. Lakukan interpolasi linier pada kedua titik interval untuk mendapatkan nilai toleransi dari batas bawah $X_{\left(r^{*}\right)}$ menggunakan persamaan berikut:

$$
X_{\left(r^{*}\right)}=\lambda_{1} X_{(r)}+\left(1-\lambda_{1}\right) X_{(r+1)}
$$

kemudian untuk batas atas $X_{\left(s^{*}\right)}$ :

$$
X_{\left(s^{*}\right)}=\lambda_{1} X_{(s)}+\left(1-\lambda_{1}\right) X_{(s-1)}
$$

dengan:

$$
\lambda_{1}=\frac{(1-p)-P(B \leq k-2)}{P(B \leq k-1)-P(B \leq k-2)}=\frac{(1-p)-P(B \leq k-2)}{P(B=k-1)}
$$

Di mana $\lambda_{1} \in[0,1]$, kemudian $X_{\left(r^{*}\right)} \in\left[X_{(r)}, X_{(r+1)}\right]$ dan $X_{\left(s^{*}\right)} \in\left[X_{(s-1)}, X_{(s)}\right]$.

2. Dengan menggunakan interpolasi yang terpendek dari hasil $\left[X_{\left(r^{*}\right)}, X_{(s)}\right]$ dan $\left[X_{(r)}, X_{\left(s^{*}\right)}\right]$, maka batas-batas kendalinya adalah:

$$
\begin{aligned}
& B \widehat{K} B=X_{\left(r^{*}\right)} \text { atau } X_{(r)} \\
& B \widehat{K} A=X_{(s)} \text { atau } X_{\left(s^{*}\right)}
\end{aligned}
$$

Sehingga, nilai estimasi untuk batas kendali bawah adalah $X_{\left(r^{*}\right)}$ atau $X_{(r)}$, dan untuk nilai estimasi batas kendali atas adalah $X_{(s)}$ atau $X_{\left(s^{*}\right)}$.

Langkah-langkah untuk ekstrapolasi:

1. Hitung batas toleransi untuk batas bawah $X_{\left(1^{*}\right)}$ dengan menggunakan persamaan berikut:

$$
X_{\left(1^{*}\right)}=\lambda_{2} X_{(2)}+\left(1-\lambda_{2}\right) X_{(1)}
$$


kemudian untuk batas atas $X_{\left(l^{*}\right)}$ menggunakan persamaan berikut:

$$
X_{\left(l^{*}\right)}=\lambda_{2} X_{(l-1)}+\left(1-\lambda_{2}\right) X_{(l)}
$$

Dimana

$$
\lambda_{2}=-\frac{(1-p)-P(B \leq l-2)}{P(B=l-2)}
$$

Dengan $\lambda_{2}<0$, kemudian $X_{\left(1^{*}\right)}<X_{(1)}$ dan $X_{\left(l^{*}\right)}>X_{(l)}$.

2. Diperoleh batas-batas kendali dari proses ekstrapolasi sebagai berikut:

$$
\begin{aligned}
& B \widehat{K} B=X_{\left(1^{*}\right)} \\
& B \widehat{K} A=X_{\left(l^{*}\right)}
\end{aligned}
$$

Sehingga, nilai estimasi untuk batas kendali bawah adalah $X_{\left(1^{*}\right)}$, dan untuk nilai estimasi batas kendali atas adalah $X_{\left(l^{*}\right)}$.

Plotkan masing-masing pengamatan dengan batas-batas kendali yang telah diperoleh, dan tentukan apakah proses dalam keadaan in-control atau out-of-control.

\section{SPC (Statistical Process Control) Fase II}

Pada beberapa literatur disebutkan bahwa penerapan diagram kendali nonparametrik didasarkan pada dua jenis, yaitu yang pertama berdasarkan rank atau peringkat, kemudian yang kedua berdasarkan analisis data kategorik. Diagram kendali dengan peringkat digunakan ketika pada suatu proses hanya terdapat satu pengamatan pada setiap titik waktunya. Beberapa jenis diagram kendali yang diajukan para ahli berdasarkan dengan peringkat diantaranya dengan menggunakan statistik yang terkenal yaitu statistik peringkat bertanda Wilcoxon (Qiu, 2018) yang didefinisikan sebagai berikut :

$$
\psi_{n}=\sum_{j=1}^{m} \operatorname{sign}\left(X_{n j}-\eta_{0}\right) R_{n j}
$$

di mana :

$\eta_{0}:$ median dari distribusi proses yang terkendali

$\operatorname{sign}(u)= \begin{cases}u=-1, & \text { jika } u<0 \\ u=0, & \text { jika } u=0 \\ u=1, & \text { jika } u>0\end{cases}$

$R_{n j}$ : peringkat dari $\left|X_{n j}-\eta_{0}\right|$

Nilai absolut dari $\psi_{n}$ akan menjadi kecil jika prosesnya terkendali, jika terjadi pergeseran rata-rata ke atas sebelum atau pada titik waktu $n$ maka nilai $\psi_{n}$ akan cenderung menjadi positif.

\section{Titik Perubahan dan Statistik Mann-Whitney}

Zhou dkk (2007) mengatakan bahwa ketika ukuran sampel referensinya cukup besar maka untuk mengestimasi parameter yang sebenarnya dapat menggunakan metode self-starting yang merupakan metode untuk memperbarui estimasi parameter dengan data pengamatan yang baru sekaligus untuk memeriksa kondisi proses yang tidak terkendali. Zhou dkk (2007) juga menjelaskan mengenai model titik perubahan untuk ukuran sampel yang tetap, dengan ukuran sampel sebesar $n$ pengamatan yang saling bebas yang terdiri dari $\left\{X_{1}, X_{2}, \ldots, X_{n}\right\}$ dimana sampel $X_{i}$ berdistribusi kontinu $F\left(x, \mu_{i}\right)$. Di mana $\mu_{i}$ menunjukkan rata-rata populasi yang merupakan parameter lokasi. Misalkan pergeseran proses terjadi pada titik $\tau$, maka:

- Pengamatan $1,2, \ldots, \tau$ distribusi prosesnya adalah $F\left(x ; \mu_{0}, \sigma_{0}^{2}\right)$,

- Pengamatan sisanya $\tau+1, \tau+2, \ldots, n$ distribusi prosesnya adalah $F\left(x ; \mu_{1}, \sigma_{1}^{2}\right)$.

Kedua hal tersebut dapat dinyatakan dalam persamaan berikut:

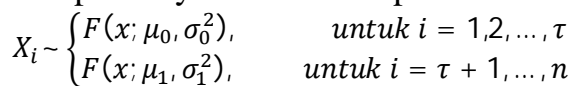


Keterangan :

$F \quad$ : fungsi distribusi yang tidak diketahui,

$\mu_{0}, \mu_{1}$ : rata-rata proses,

$\sigma_{0}^{2}, \sigma_{1}^{2}$ : varians proses,

Jika $\mu_{0} \neq \mu_{1}$ atau $\sigma_{0}^{2} \neq \sigma_{1}^{2}$, maka $\tau$ dikatakan sebagai titik perubahan.

Pada saat mendeteksi dan menemukan perubahan rata-rata atau titik perubahan maka perlu dilakukan pengujian nonparametrik, salah satunya dengan menggunakan statistika nonparametrik yang diajukan oleh Mann-Whitney (1947) pada Wang dkk (2016) yang dikenal dengan metode uji dua sampel Mann-Whitney yang digunakan untuk mendeteksi perbedaan pada distribusi dua populasi melalui dua kelompok sampel yang saling bebas. Untuk $1 \leq t<$ $n$, maka statistik Mann-Whitney nya adalah :

$$
M W_{t, n}=\sum_{i=1}^{t} \sum_{j=t+1}^{n} I\left(x_{j}<x_{i}\right)=\sum_{j=t+1}^{n}\left[I\left(x_{j}<x_{1}\right)+I\left(x_{j}<x_{2}\right)+\cdots+I\left(x_{j}<x_{t}\right)\right]
$$

Di mana : $I\left(x_{j}<x_{i}\right)=\left\{\begin{array}{ll}1, & \text { untuk } x_{j}<x_{i} \\ 0, & \text { untuk } x_{j} \geq x_{i}\end{array}\right.$,

Di mana $t=m-m_{0}-1$ dan $j=m-m_{0}$. Jika $\mu_{0}=\mu_{1}$ atau $\sigma_{0}^{2}=\sigma_{1}^{2}$, maka proses dikatakan dalam keadaan terkendali, sebaliknya jika $\mu_{0} \neq \mu_{1}$ atau $\sigma_{0}^{2} \neq \sigma_{1}^{2}$, maka proses dikatakan dalam keadaan tidak terkendali dan dapat dinyatakan bahwa terjadi pergeseran ratarata atau varians pada data. Pada Zhou dkk (2007) untuk menentukan ekspektasi atau rataan dan variansnya dapat digunakan persamaan berikut:

$$
\begin{gathered}
E_{0}\left(M W_{t, n}\right)=\frac{t(n-t)}{2} \\
\operatorname{Var}_{0}\left(M W_{t, n}\right)=\frac{t(n-t)(n+1)}{12}
\end{gathered}
$$

Namun, jika terdapat ties (pada data terdapat dua atau lebih nilai yang sama, sehingga peringkatnya dirata-ratakan) pada data, maka dilakukan perbaikan pada varians $M W_{t, n}$ yang diperoleh dengan mengalikan faktor :

$$
1-\sum_{i=1}^{r} g_{i}\left(g_{i}^{2}-1\right) n^{-1}\left(n^{2}-1\right)^{-1}
$$

$r$ merupakan banyaknya nilai yang berbeda pada $n$ pengamatan dan nilai ke- $i$ yang diperoleh dari frekuensi $g_{i}\left(\sum_{i=1}^{r} g_{i}=n\right)$. Sehingga pada situasi ketika terdapat ties pada data, maka varians dari $M W_{t, n}$ yang terkendali adalah :

$$
\operatorname{Var}_{0}\left(M W_{t, n}\right)=\frac{t(n-t)(n+1)}{12}\left(1-\sum_{i=1}^{r} g_{i}\left(g_{i}^{2}-1\right) n^{-1}\left(n^{2}-1\right)^{-1}\right)
$$

Maka statistik Mann-Whitney terstandarisasinya didefinisikan :

$$
S M W_{t, n}=\frac{M W_{t, n}-E_{0}\left(M W_{t, n}\right)}{\sqrt{\operatorname{Var}_{0}\left(M W_{t, n}\right)}}
$$

Berdasarkan hasil dari Mann-Whitney (1947), Wang dkk (2016) menyimpulkan bahwa:

1. Distribusi $S M W_{t, n}$ yang simetris disekitar nol maka proses dinyatakan terkendali,

2. Nilai $S M W_{t, n}$ yang besar mengindikasikan bahwa terjadi pergeseran rata-rata positif,

3. Nilai $S M W_{t, n}$ yang kecil mengindikasikan bahwa terjadi pergeseran rata-rata negatif.

\section{Diagram Kendali CUSUM Nonparametrik}

Zhou dkk (2007) melakukan beberapa modifikasi pada nilai maksimum statistik MannWhitney $T_{n}$ yang dibakukan yang didefinisikan sebagai berikut :

$$
T_{m, n}=\max _{m-m_{0} \leq t<m+n}\left|S M W_{t,(m+n)}\right|
$$

Dimana $m$ merupakan banyaknya data pengamatan yang dinyatakan terkendali melalui JRS is licensed under Creative Commons AttributionNonCommercial-ShareAlike 4.0 International License. 
proses SPC fase I, dan $n$ merupakan banyak pengamatan yang digunakan untuk proses SPC fase II. Menurut Srivasta dan Wu (1993) dalam Wang dkk, (2016) meskipun diagram CUSUM dan EWMA sama-sama baik dalam mendeteksi pergeseran rata-rata yang kecil, namun berdasarkan pengukuran kinerjanya menggunakan $A R L$ diperoleh diagram kendali CUSUM sedikit lebih sensitif dibandingkan diagram kendali EWMA.

Statistik uji dari diagram kendali CUSUM nonparametrik Mann-Whitney yang diajukan oleh Wang dkk (2016) :

$$
\begin{aligned}
& S_{j}^{+}(m, n)=\max \left\{0, S_{j-1}^{+}(m, n)+S M W_{j,(m+n)}-k\right\} \\
& S_{j}^{-}(m, n)=\min \left\{0, S_{j-1}^{-}(m, n)+S M W_{j,(m+n)}+k\right\}
\end{aligned}
$$

Dengan $j=m-m_{0}, m-m_{0}+1, \ldots, m-m_{0}+n-1$, untuk $0 \leq m_{0} \leq m$, sehingga $S_{m-m_{0}-1}^{+}(m, n)=S_{m-m_{0}-1}^{-}(m, n)=0$. Di mana $m_{0}$ merupakan nilai awal yang dapat ditentukan oleh peneliti dengan rentangan $[4,10]$, jika $m \geq 10$. Sedangkan $m$ merupakan banyaknya data pengamatan yang sudah dinyatakan terkendali melalui proses SPC fase I, kemudian untuk $n$ merupakan data pengamatan yang sedang dipantau untuk proses SPC fase II, dan $k$ merupakan nilai referensi dimana Wang dkk (2016), mengambil nilai $k=0,5$. Didefinisikan:

$$
\begin{aligned}
& S_{\text {max }}^{+}(m, n)=\max _{m-m_{0} \leq j \leq m+n-1} S_{j}^{+}(m, n) \\
& S_{\text {min }}^{-}(m, n)=\min _{m-m_{0} \leq j \leq m+n-1} S_{j}^{-}(m, n)
\end{aligned}
$$

Aturan dari diagram kendali yang diajukan Wang, dkk (2016) adalah:

1. Setelah diperoleh sampel ke- $n$, hitung $S_{\max }^{+}(m, n)$ dan $S_{\min }^{-}(m, n)$.

2. Tentukan nilai kritis $h_{m, n}$ (dapat dilihat pada Lampiran Tabel 3).

3. Jika $S_{\max }^{+}(m, n) \leq h_{m, n}$ atau $S_{\min }^{-}(m, n) \geq-h_{m, n}$, maka disimpulkan bahwa tidak tersedia cukup bukti yang menunjukkan terjadinya pergeseran, kemudian lanjutkan untuk pemantauan sampel selanjutnya yang ke- $(n+1)$.

4. Jika $S_{\max }^{+}(m, n)>h_{m, n}$ atau $S_{\min }^{-}(m, n)<-h_{m, n}$, maka diidentifikasikan terdapat sinyal yang menyatakan proses dalam keadaan tidak terkendali. Di mana untuk $S_{\text {max }}^{+}(m, n)>h_{m, n}$ menunjukkan terjadinya pergeseran rata-rata ke atas, sedangkan untuk $S_{\min }^{-}(m, n)<-h_{m, n}$ menunjukkan terjadinya pegeseran rata-rata ke bawah.

\section{Hasil Penelitian dan Pembahasan}

\section{SPC Fase I}

Diperoleh jumlah sampel yang tersedia adalah sebanyak $l=43$ data. Untuk menentukan ukuran sampel minimum interval toleransi dua sisi $l_{2}\left(\alpha_{t o l}, p\right)$ pada tabel 2.1 maka digunakan $\alpha_{\text {tol }}=0,05$ dan $p=0,20$ dan diperoleh nilai $l_{2}\left(\alpha_{t o l}, p\right)=59$. Karena $l=43<$ $l_{2}(0,05 ; 0,20)=59$ maka untuk proses perhitungan batas-batas kendalinya digunakan metode ekstrapolasi.

Diperoleh perhitungan untuk masing-masing batas toleransi $X_{\left(1^{*}\right)}$ dengan menggunakan persamaan (6) berikut ini:

$$
\begin{aligned}
X_{\left(1^{*}\right)} & =(-0,5788783567) \times 39.279 .999+(1-(-0,5788783567)) \times 38.110 .001 \\
& =(-22.738 .341)+60.171 .055,75 \\
& =37.432 .714,75
\end{aligned}
$$

kemudian untuk batas atas $X_{\left(l^{*}\right)}$ menggunakan persamaan (7) berikut:

$$
\begin{aligned}
X_{\left(l^{*}\right)} & =(-0,5788783567) \times 62.700 .001+(1-(-0,5788783567)) \times 62.840 .000 \\
& =(-36.295 .673,54)+99.216 .715,94 \\
& =62.921 .042,4
\end{aligned}
$$

Sehingga, berdasarkan persamaan (8) diperoleh batas-batas kendali dari proses ekstrapolasi yaitu $B \widehat{K} B=37.432 .714,75$ dan $B \widehat{K} A=62.921 .042,4$.

Selanjutnya plotkan masing-masing data dengan batas kendali bawah dan batas kendali atas yang diperoleh di atas, yang disajikan pada diagram kendali pada Gambar 1. 


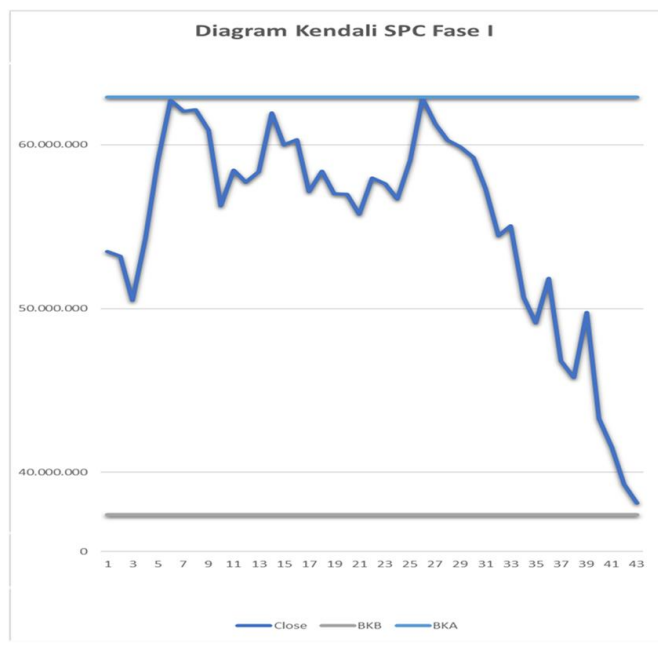

Gambar 1 Diagram Kendali SPC Fase I

Dari diagram kendali pada Gambar 1 dapat dilihat bahwa semua data berada diantara batas-batas kendali, sehingga proses dinyatakan dalam keadaan in-control. Jadi, data sebanyak 43 buah yang diperoleh dari proses SPC fase I dapat dijadikan sebagai sampel referensi untuk proses pemantauan pada SPC fase II diagram kendali nonparametrik CUSUM berdasarkan statistik Mann-Whitney.

\section{Diagram Kendali CUSUM Nonparametrik Berdasarkan Statistik Mann-Whitney}

Pada proses SPC fase I telah diperoleh sampel referensi sebanyak $m=43$ dan dipilih nilai referensi $m_{0}=4$. Selanjutnya untuk proses SPC fase II dilakukan pemantauan pada data proses $x_{j}$ dengan $j=t+1, t+2, \ldots, n$. Kemudian dilakukan perhitungan statistik Mann-Whitney menggunakan persamaan (12) dengan data sampel referensi $x_{i}$ sebagai kelompok sampel pertama dengan $t=38$ dan $j=39$ karena $j=m-m_{0}$, sehingga diperoleh hasil perhitungan statistik Mann-Whitney untuk proses pemantauan pengamatan pertama $m+n=44$ yang disajikan pada Tabel 2.

Tabel 2 Hasil Perhitungan Statistik Mann-Whitney

\begin{tabular}{|c|c|}
\hline$j$ & $M W_{t, m+n}$ \\
\hline 39 & 35 \\
\hline 40 & 38 \\
\hline 41 & 38 \\
\hline 42 & 38 \\
\hline 43 & 38 \\
\hline 44 & 38 \\
\hline
\end{tabular}

Perhitungan lanjut pada statistik Mann-Whitney yang terstandarisasi dilakukan menggunakan perhitungan nilai rataan atau ekspektasi dengan nilai varians dari data dengan menggunakan persamaan (13) berikut ini:

$$
\begin{gathered}
E_{0}\left(M W_{t, m+n}\right)=\frac{38(44-38)}{2}=114 \\
\operatorname{Var}_{0}\left(M W_{t, m+n}\right)=\frac{38(44-38)(44+1)}{12}=855
\end{gathered}
$$

Dari hasil perhitungan diatas diperoleh nilai rataan dari data sebesar 114, sedangkan varians dari data sebesar 855. Dengan menggunakan nilai rataan dan simpangan baku selanjutnya dilakukan perhitungan statistik Mann-Whitney yang terstandarisasi menggunakan persamaan (15) dan diperoleh hasil yang disajikan pada Tabel 3. 
90 |Zakiyatis Salmaini.

Tabel 3 Hasil Perhitungan Statistik Mann-Whitney yang Terstandarisasi

\begin{tabular}{|c|c|}
\hline$j$ & $S M W_{t, m+n}$ \\
\hline 39 & $-2,70174$ \\
\hline 40 & $-2,59915$ \\
\hline 41 & $-2,59915$ \\
\hline 42 & $-2,59915$ \\
\hline 43 & $-2,59915$ \\
\hline 44 & $-2,59915$ \\
\hline
\end{tabular}

Dengan nilai statistik Mann-Whitney yang terstandarisasi pada Tabel 3 dapat dihitung nilai statistik Mann-Whitney $T_{m, n}$ pada persamaan (16) berikut ini:

$$
T_{m, n}=\max _{m-m_{0} \leq t<m+n}\left|S M W_{t,(m+n)}\right|=2,70174
$$

Berdasarkan nilai $T_{m, n}$ tersebut dapat diambil keputusan dengan menggunakan nilai $h_{m, n}=1,661$ maka dinyatakan terdapat sinyal yang menyatakan bahwa proses dalam keadaan tidak terkendali karena $T_{m, n}=2,70174>h_{m, n}=1,661$.

Berdasarkan nilai statistik Mann-Whitney yang terstandarisasi pada masing-masing $j$ dapat dilakukan perhitungan statistik uji dari diagram kendali CUSUM nonparametrik menggunakan persamaan (17) dengan menggunakan nilai $k=0,5$ sebagai nilai referensi sehingga diperoleh nilai statistik uji dari diagram kendali CUSUM nonparametrik MannWhitney yang diajukan Wang dkk (2016) yang disajikan pada Tabel 4.

Tabel 4 Hasil Perhitungan Statistik Uji Diagram Kendali

\begin{tabular}{|c|c|c|}
\hline$j$ & $S_{j}^{+}(m, n)$ & $S_{j}^{-}(m, n)$ \\
\hline 38 & 0 & $\min \{0 ;-2,20174\}=-2,20174$ \\
\hline 39 & $\max \{0 ;-3,20174\}=0$ & $\min \{0 ;-4,30089\}=-4,30089$ \\
\hline 40 & $\max \{0 ;-6,30089\}=0$ & $\min \{0 ;-6,40003\}=-6,40003$ \\
\hline 41 & $\max \{0 ;-9,40003\}=0$ & $\min \{0 ;-8,49918\}=-8,49918$ \\
\hline 42 & $\max \{0 ;-12,4992\}=0$ & $\min \{0 ;-10,5983\}=-10,5983$ \\
\hline 43 & $\max \{0 ;-15,5983\}=0$ & \\
\hline
\end{tabular}

Berdasarkan hasil perhitungan pada Tabel 3 diperoleh nilai statistik uji berdasarkan persamaan (18) adalah:

$S_{\max }^{+}=0$

$S_{\text {min }}^{-a x}=-10,5983$

Menentukan apakah terjadi pergeseran atau tidak maka pengambilan keputusan dilakukan berdasarkan kriteria uji jika $S_{\max }^{+}(m, n) \leq h_{m, n}$ atau $S_{\min }^{-}(m, n) \geq-h_{m, n}$, maka disimpulkan bahwa tidak tersedia cukup bukti yang menunjukkan terjadinya pergeseran, kemudian lanjutkan untuk pemantauan sampel selanjutnya yang ke- $(n+1)$, sebaliknya jika $S_{\max }^{+}(m, n)>h_{m, n}$ atau $S_{\min }^{-}(m, n)<-h_{m, n}$, maka diidentifikasikan terdapat sinyal yang menyatakan proses dalam keadaan tidak terkendali. Dengan mengambil $\alpha=0,05$ maka pada tabel nilai keputusan dapat digunakan $m=10$ dan $n=1$ maka digunakan nilai $h_{m, n}=1,184$ pada $A R L_{0}=370$.

\section{Karena}

$S_{\text {max }}^{+}=0<h_{m, n}=1,184$

$S_{\text {min }}^{-}=-10,5983<-h_{m, n}=-1,184$

Nilai $S_{\min }^{-}=-10,5983<-h_{m, n}=-1,184$ menunjukkan terjadinya pergeseran ratarata kebawah, sehingga dapat diambil keputusan bahwa pada data harga close saham (PT). X diidentifikasi terdapat sinyal yang menyatakan terjadi pergeseran rata-rata pada proses 
pemantauan hari pertama, maka harga close saham (PT). X dinyatakan dalam keadaan tidak terkendali.

\section{Kesimpulan}

Berdasarkan analisis dan pembahasan yang dilakukan maka peneliti menyimpulkan bahwa data harga close saham (PT). X yang digunakan untuk penerapan diagram kendali CUSUM nonparametrik berdasarkan statistik Mann-Whitney teridentifikasi terjadi pergeseran rata-rata proses ke bawah pada proses pemantauan hari ke-1. Hal tersebut menunjukkan bahwa pada data harga close saham (PT). X pada titik ke-44 mengalami downtrend (trend menurun), sehingga data harga close saham (PT). X dinyatakan dalam keadaan tidak terkendali.

\section{Acknowledge}

Penulis mengucapkan terima kasih sebesar-besarnya kepada semua pihak terkait yang selalu mendukung penulis selama melakukan penelitian ini.

\section{Daftar Pustaka}

[1] Damayanti, F. 2020. Aplikasi Interval Toleransi Nonparametrik pada Diagram Kendali dan Penerapannya pada Data Ultimate Tensile Strength Lempengan Aluminium. Bandung: Program Studi Statistika, Fakultas Matematika dan Ilmu Pengetahuan Alam, Universitas Islam Bandung.

[2] Edusaham.com. 2019. Penting! Inilah 3 Hal yang Perlu Diperhatikan Sebelum Membeli Saham.

[3] Graham, M.A., Human, S.W., Chakraborti, S. 2009. A Phase I Nonparametric ShewhartType Control Chart based on the Median. Journal of Applied Statistics, Vol. 37, No.11, 17951813.

[4] Qiu, P. (2018). Some Perspectives on Nonparametric Statistical Process Control. Journal of Quality Technology, Vol.50, No.01, 49-65.

[5] Wang, P., Zhang, L., Xiong, Q. 2016. A Nonparametric CUSUM Control Chart based on the Mann-Whitney Statistic. Communications in Statistics-Theory and Methods.

[6] Zhou, C., Zou, C., Zhang, Y., Wang, Z. 2007. Nonparametric Control Chart based on Change-Point Model. Statistical Papers, Vol.50, 13-28. 